University of Nebraska - Lincoln

DigitalCommons@University of Nebraska - Lincoln

Faculty Publications, Department of Psychology

Psychology, Department of

8-7-2006

\title{
Effect of Nicotine on Negative Affect Among More Impulsive Smokers
}

\author{
Neal Doran \\ University of Illinois at Chicago \\ Dennis E. McChargue \\ University of Nebraska-Lincoln, dmcchargue2@unl.edu \\ Bonnie Springs \\ University of Illinois at Chicago \\ Joe VanderVeen \\ University of Illinois at Chicago \\ Jessica Werth Cook \\ Puget Sound Veterans Affairs Hospital, jwcook@ctri.wisc.edu \\ See next page for additional authors
}

Follow this and additional works at: https://digitalcommons.unl.edu/psychfacpub

Part of the Psychiatry and Psychology Commons

Doran, Neal; McChargue, Dennis E.; Springs, Bonnie; VanderVeen, Joe; Werth Cook, Jessica; and Richmond, Malia, "Effect of Nicotine on Negative Affect Among More Impulsive Smokers" (2006). Faculty Publications, Department of Psychology. 304.

https://digitalcommons.unl.edu/psychfacpub/304

This Article is brought to you for free and open access by the Psychology, Department of at DigitalCommons@University of Nebraska - Lincoln. It has been accepted for inclusion in Faculty Publications, Department of Psychology by an authorized administrator of DigitalCommons@University of Nebraska - Lincoln. 


\section{Authors}

Neal Doran, Dennis E. McChargue, Bonnie Springs, Joe VanderVeen, Jessica Werth Cook, and Malia Richmond 


\title{
Effect of Nicotine on Negative Affect Among More Impulsive Smokers
}

\author{
Neal Doran \\ University of Illinois at Chicago \\ Joe VanderVeen \\ University of Illinois at Chicago
}

\author{
Dennis McChargue and Bonnie Spring \\ University of Illinois at Chicago and Hines Veterans \\ Affairs Hospital \\ Jessica Werth Cook \\ Puget Sound Veterans Affairs Hospital
}

\author{
Malia Richmond \\ University of Illinois at Chicago
}

\begin{abstract}
In the present study, the authors tested the hypothesis that nicotine would provide greater relief from negative affect for more impulsive smokers than for less impulsive smokers. Euthymic adult smokers $(N=70)$ participated in 2 laboratory sessions, during which they underwent a negative mood induction (music + autobiographical memory), then smoked either a nicotinized or de-nicotinized cigarette. Mixed-effects regression yielded a significant Impulsivity $\times$ Condition (nicotinized vs. de-nicotinized) $\times$ Time interaction. Simple effects analyses showed that heightened impulsivity predicted greater negative affect relief after smoking a nicotinized cigarette but not after smoking a de-nicotinized cigarette. These data suggest that nicotine may be a disproportionately powerful negative reinforcer for highly impulsive smokers, promoting higher levels of nicotine dependence and inhibiting smoking cessation.
\end{abstract}

Keywords: impulsivity, nicotine, negative affect

\begin{abstract}
Although relatively effective smoking cessation techniques have been developed (U.S. Department of Health and Human Services, 2000), nearly a quarter of American adults continue to smoke (Centers for Disease Control, 2002). Researchers have hypothesized that remaining smokers may be members of specific subgroups that derive particular benefits from smoking or have greater difficulty quitting. Most of this work has focused either on smokers
\end{abstract}

Neal Doran, Joe VanderVeen, and Malia Richmond, Department of Psychology, University of Illinois at Chicago; Dennis McChargue and Bonnie Spring, Department of Psychology, University of Illinois at Chicago and Psychology Service, Hines Veterans Affairs Hospital, Hines, Illinois; Jessica Werth Cook, Psychology Service, Puget Sound Veterans Affairs Hospital, Seattle, Washington.

Dennis McChargue is now at the Department of Psychology, University of Nebraska-Lincoln. Bonnie Spring is now at the Department of Preventative Medicine, Feinberg Medical School, Northwestern University.

This research was supported by American Heart Association Grant 0410025Z to Neal Doran, a Veterans Affairs Merit Award to Bonnie Spring, and National Institute on Drug Abuse National Research Service Award DA14144 to Jessica Werth Cook.

Correspondence concerning this article should be addressed to Neal Doran, Department of Psychology, University of Illinois at Chicago, MC 285, 1007 West Harrison Street, Chicago, IL 60607. E-mail: ndoran1@uic.edu who are particularly vulnerable to major depression (e.g., Hall et al., 1998; Hall, Munoz, \& Reus, 1994; Hitsman, Borrelli, McChargue, Spring, \& Niaura, 2003) or on smokers who are especially concerned about postcessation weight gain (e.g., Jeffery, Hennrikus, Lando, Murray, \& Liu, 2000; Meyers et al., 1997). Less research has explored personality traits that may contribute to the maintenance of regular smoking and heighten the difficulty of cessation. The aim of the current study was to test the hypothesis that one such trait, impulsivity, would be associated with acute affective response to nicotine administration, a mechanism that has been thought to maintain drug use.

Impulsivity has consistently been shown to be associated with substance abuse (Moeller \& Dougherty, 2002), including cigarette smoking (e.g., Baker, Brandon, \& Chassin, 2004; Doran, Spring, McChargue, Pergadia, \& Richmond, 2004; Kassel, Shiffman, Gnys, Paty, \& Zettler-Segal, 1994). It is commonly thought that impulsive individuals are motivated to use drugs via an appetitive pathway. That is, impulsive individuals appear to be hypersensitive to reward (L. E. Martin \& Potts, 2004) and to have disproportionate difficulty inhibiting approach behavior in the presence of immediately rewarding stimuli (Arnett \& Newman, 2000). However, other research has suggested that the link between impulsivity and substance use may not be purely appetitive. In particular, there may be an additional and overlooked pathway linking impulsivity with substance abuse and dependence via negative affect. 
First, impulsive individuals appear to experience bouts of negative affect more frequently than others (Emmons \& Diener, 1986). This finding is consistent with conceptualizations of impulsivity as a combination of appetitive traits and negative affect-related traits. For example, in the fivefactor model of personality, impulsivity is included as a component of both extraversion and neuroticism (Costa \& McCrae, 1992). Similarly, in Gray's $(1970,1987)$ approach/ avoidance model of personality, impulsive individuals are thought to have overactive behavioral approach systems and hypoactive behavioral inhibition systems. Finally, considerable previous research has suggested that impulsivity and related behaviors (e.g., aggression), like negative affect, may be associated with decreased serotonergic functioning (e.g., Coccaro et al., 1989; Evans, Platts, Lightman, \& Nutt, 2000; Manuck et al., 1998; Reist, Helmeste, Albers, Chhay, \& Tang, 1996; Walderhaug et al., 2002), although some studies have failed to find such an association (e.g., Coccaro, Kavoussi, Sheline, Berman, \& Csernansky, 1997; LeMarquand et al., 1998; Mulder \& Joyce, 2002).

Second, there is evidence to suggest that impulsive individuals may be disproportionately likely to turn to substance use as a means of alleviating negative affect. For example, in a large-scale survey of adolescent drinking behavior, Cooper, Agocha, and Sheldon (2000) found that teens with higher levels of impulsivity and of neuroticism were more likely than other teens to use alcohol to cope with negative moods. Similarly, Hussong and Chassin (1994) reported that impulsive adolescents drank more heavily on days they reported elevated negative affect than other days, unlike their less impulsive peers. Finally, research has indicated that behaviorally undercontrolled (i.e., impulsive and aggressive) individuals experience a greater reduction in the physiological symptoms of stress following alcohol consumption than others (Sher, 1987) and that behaviorally undercontrolled adolescents expect greater stress reduction from alcohol (Mann, Chassin, \& Sher, 1987). In sum, research has suggested that impulsive individuals may experience negative affect more frequently than others and that they may be particularly susceptible to substance abuse as a means of coping with negative affect.

Third, the link between impulsivity and negative affect may be particularly relevant for impulsive smokers, given that smokers tend to experience chronic bouts of stress or negative affect (Parrott, 1999). For example, research has shown increased negative affect during periods of nicotine abstinence (Hughes, Higgins, \& Hatsukami, 1990; Parrott, 1994; Parrott, Garnham, Wesnes, \& Pincock, 1996). Moreover, negative affect is a product of smoking cessation (Wetter et al., 2000) and heightens risk for both lapse and relapse (Kenford et al., 2002; Piasecki, Kenford, Smith, Fiore, \& Baker, 1997; Shiffman, Paty, Gnys, Kassel, \& Hickox, 1996). Consequently, to the extent that smoking provides at least temporary relief from negative affect (Piasecki et al., 1997; Salin-Pascual, 2002a, 2002b; SalinPascual \& Drucker-Colin, 1998; Salin-Pascual, Rosas, Jimenez-Genchi, Rivera-Meza, \& Delgado-Parra, 1996), it may be particularly reinforcing for impulsive individuals, who may be disproportionately prone to smoke to ameliorate negative affect.

Impulsive drug users are generally thought to be motivated to use drugs by appetitive processes. However, findings that drug use among such individuals is increased during bouts of negative affect and that they may have greater expectations for distress relief from drugs have suggested that impulsive drug users may also be motivated by a desire to alleviate negative affect. The goal of the current study was to examine the basis for such motivation among impulsive smokers by testing the hypothesis that more impulsive smokers derive greater relief from negative affect following nicotine administration than other smokers.

\section{Method}

\section{Participants}

The present study was a secondary analysis of a larger experiment investigating the link between affect and smoking among euthymic smokers with and without a history of major depression as well as currently depressed smokers. Currently depressed smokers were excluded from the present study. Participants $(N=70$; $51 \%$ female) were community members between the ages of 18 and 65 years $(M=29.9$ years, $S D=10.5)$ who had smoked 15 or more cigarettes per day for at least the past year and who were moderately nicotine dependent (Fagerström Test for Nicotine Dependence [FTND], $M=5.4, S D=1.6$; Heatherton, Kozlowski, Frecker, \& Fagerström, 1991). Mean cigarette consumption was 20.3 cigarettes per day $(S D=7.7)$, and participants had been regular smokers for an average of 12.4 years $(S D=10.1)$. Approximately $43 \%(n=30)$ had a history of two or more episodes of major depression.

Participants were recruited by newspaper and electronic mailing list advertisements and by flyers posted around the community, and they were paid to participate in one screening session and four experimental sessions. Study candidates were excluded if they were currently using nicotine replacement products, met criteria for any Axis I disorder other than nicotine dependence or major depressive disorder within the past 6 months, had been treated for substance abuse within the past year, or had difficulty completing mood questionnaires (i.e., expressed unfamiliarity with mood descriptors). Perimenopausal women were also excluded, as the transition to menopause appears to be associated with increased susceptibility to negative affect (Khine, Luff, Rubinow, \& Schmidt, 2003; Soares \& Almeida, 2001). Perimenopausal status was determined by self-report of symptoms (e.g., irregular menstrual cycle with at least one menstrual period during the past year).

\section{Measures}

Axis I disorders. To determine whether participants met criteria for a current Axis I disorder, trained diagnosticians administered the Structured Clinical Interview for DSM-IV, Nonpatient Version (SCID-NP; Spitzer, Williams, Gibbon, \& First, 1992). Diagnosticians were supervised by clinical psychologists to assess the reliability and accuracy of the assessments. The SCID-NP (Spitzer et al., 1992) has moderate construct validity, as shown by its favorable comparison with other diagnostic assessment methods (Williams et al., 1992).

Impulsivity. The Barratt Impulsiveness Scale, Version 11 (BIS-11; Patton, Stanford, \& Barratt, 1995) provides a measure of 
trait impulsivity, defined as tending to be oriented toward the present rather than the future (i.e., having difficulty delaying gratification), to act without considering the consequences, and to make quick cognitive decisions (Patton et al., 1995). The BIS-11 is a self-report questionnaire that asks participants to rate how often a series of statements applies to them. Cumulative scores range from 30 (low in impulsivity) to 120 (high in impulsivity). The average BIS-11 score in the present sample was $68.0(S D=8.5)$. The BIS-11 has three subscales: Nonplanning Impulsiveness, Attentional Impulsiveness, and Motor Impulsiveness. The BIS-11 has been shown to be reliable in both clinical and community samples, with Cronbach's alpha coefficients ranging from .79 to .83 (Patton et al., 1995). The BIS-11 is structured to assess longterm patterns of behavior and has been used to assess trait levels of impulsivity across a variety of populations, including substancedependent individuals (e.g., Mitchell, 1999; Moeller et al., 2002; Stanford, Greve, Boudreaux, Mathias, \& Brumbelow, 1996).

Nicotine dependence. The FTND was used to assess level of nicotine dependence. Because some research has suggested that more dependent smokers experience greater subjective mood fluctuation between cigarettes (Parrott, 1994), FTND has been used as a covariate to statistically control for potential individual differences resulting from variation in nicotine dependence. The sixitem FTND scale sums behavioral characteristics suggestive of physiological dependence on nicotine (e.g., smoking soon after awakening or when ill). The FTND has demonstrated adequate internal consistency (Cronbach's $\alpha=.64$; Pomerleau, Carton, Lutzke, \& Flessland, 1994) and strong test-retest reliability over a 3-week period ( $r=.88, p<.01, n=60$; Pomerleau et al., 1994).

Negative memory questionnaire. A negative memory questionnaire was administered during screening to obtain autobiographical memories to serve for the negative mood inductions. Four negative memories were collected. For each memory, participants reported on a 10-point scale ranging from 1 (extremely sad) to 10 (not at all sad) how sad or upset each memory made them and how vivid each memory was. Two memories were selected for the experimental conditions that were similar with respect to how negative and vivid the memories were.

Smoking status. At screening, participants reported their average daily level of smoking. At the beginning of each experimental session, participants were asked to report their smoking status and whether they smoked their typical amount up until the session. At screening and at the beginning of each experimental session, participants' smoking status was also assessed via ecolyzer (EC50, Vitalograph, Inc., Lenexa, KS), yielding a measure of expired $\mathrm{CO}$. Candidates whose $\mathrm{CO}$ measured less than $8 \mathrm{ppm}$ at screening were excluded from participation. Participants with $\mathrm{CO}$ values less than $8 \mathrm{ppm}$ on arrival for experimental sessions were rescheduled. They were reminded to smoke their usual amount prior to the next experimental session to standardize baseline nicotine exposure at the start of testing and to minimize withdrawal effects.

Negative affect. Negative affect was assessed via the Profile of Mood States (POMS; McNair, Lorr, \& Droppleman, 1971). Factor analytic studies have shown that the POMS contains six subscales: Tension/Anxiety, Depression/Dejection, Anger/Hostility, Vigor/ Activity, Fatigue/Inertia, and Confusion/Bewilderment. All subscales have been shown to be internally consistent (Cronbach's alpha coefficients approaching .90) and contain evidence of construct and predictive validity (McNair et al., 1971). The outcome measure was a composite Dysphoria subscale, derived by summing the Tension/Anxiety, Depression/Dejection, and Anger/Hostility subscales. The Dysphoria subscale contains a total of 36 items rated on a 4-point scale ranging from 0 (not at all) to 4 (extremely), yielding a possible score range of 0 to 144 . The
POMS was administered at baseline of each experimental session, $10 \mathrm{~min}$ after the mood induction as a manipulation check, 2 min postcigarette, and $32 \mathrm{~min}$ postcigarette. Across conditions, the average POMS Dysphoria score at baseline was $10.1(S D=12.4)$.

Cigarette characteristic rating scale. A cigarette characteristic rating scale, which measured cigarette taste and likability (Pickworth, Fant, Nelson, Rohrer, \& Henningfield, 1999), was used to assess potential differences between nicotinized and denicotinized cigarettes. Scale items, rated on 10 point Likert-type scales ranging from 1 (not at all) to 10 (extremely), include properties such as strength, harshness, and taste. Participants completed the scale at each experimental session after smoking the experimental cigarette for that session. Participants also rated their usual brand of cigarettes with the same scale during the baseline assessment period.

\section{Procedure}

All smokers in the current sample participated in the parent study, which consisted of a total of four experimental sessions. The parent study was designed to examine the influence of a history of major depression on the relationship between affect and nicotine. The two experimental sessions composing the present study were designed to assess whether nicotine differentially modulates negative affect among smokers with a positive depression history. The other two experimental sessions, which were excluded from the present study, tested whether nicotine would induce a disproportionate increase in enjoyment of pleasurable activities for smokers with a history of depression.

Candidates contacted study staff via telephone and completed a brief telephone screening process. Candidates who met age and smoking status requirements were then interviewed in person with the SCID-NP diagnostic interview (Spitzer et al., 1992). A practice mood induction was performed to ensure the participant was capable of responding to a negative mood induction. Participants completed the POMS before and after the practice induction; those who reported an increase of at least 4 points on the POMS Dysphoria subscale were considered responsive. Prior to the end of the screening session, participants completed the negative memory questionnaire, FTND, BIS-11, and questionnaires assessing smoking history.

Participants were tested individually. Experimental sessions were administered in a counterbalanced fashion. Female participants were tested between Days 7 and 21 of their menstrual cycle to minimize possible influences of hormonal fluctuation on affective responses. All sessions were scheduled after 11 a.m. and lasted approximately $2 \mathrm{hr}$. Participants were not restricted in how much they smoked before each session and were encouraged to smoke "as normal" prior to the trial. All sessions were scheduled at least $24 \mathrm{hr}$ apart to reduce the likelihood of practice effects.

Immediately before each experimental session, participants' $\mathrm{CO}$ was assessed via ecolyzer, after which they smoked one of their own cigarettes to ensure that they were not in nicotine withdrawal at the beginning of the session. Participants then completed questionnaires prior to undergoing the 10 -min negative-mood-induction procedure. The mood-induction procedure involved two components: listening to sad music and imagining a negative autobiographical memory. The musical component of the induction included excerpts from Prokofiev's Russia Under the Mongolian Yoke and Barber's Adagio Pour Cordes, both of which have been shown to induce dysphoric moods (Clark \& Teasdale, 1985; Gerrards-Hesse, Spies, \& Hesse, 1994; M. Martin, 1990). Participants were instructed to sit quietly for $10 \mathrm{~min}$ and to recall a specific negative autobiographical memory while listening to the music. Following the negative mood induction by $3 \mathrm{~min}$, participants' 
levels of negative affect were assessed with the POMS, after which they were instructed to smoke either a nicotinized or de-nicotinized cigarette ( $7 \mathrm{~min}$ postinduction). Following the cigarette, participants filled out additional mood and nicotine-withdrawal questionnaires (13 and $43 \mathrm{~min}$ postinduction, 2 and $32 \mathrm{~min}$ after smoking). At the end of each session, a tape of uplifting music was played and mood was again assessed to ensure that participants' negative affect was not elevated relative to baseline.

Nicotinized/de-nicotinized smoking conditions. Nicotinized cigarettes (1.0 mg nicotine) and de-nicotinized cigarettes $(0.1 \mathrm{mg}$ nicotine) were contrasted so that the pharmacological effects of nicotine could be examined while holding constant the sensory effects of smoking. Nicotinized and de-nicotinized cigarettes were both produced by Lifetech Corp., Lafayette Hill, PA, and were matched for tar and CO content. Nicotinized and de-nicotinized cigarettes were presented in counterbalanced order.

Analytic plan. Negative affect was analyzed across the four time points (baseline, postinduction mood check, 2 min postcigarette, 32 min postcigarette) via mixed-effects regression modeling. By including baseline negative affect in the time-varying dependent variable, the analyses accounted for any differences in negative affect at baseline. Mixed-effects regression is also known as multilevel modeling (Goldstein, 1995), random-effects regression modeling (Persky, Spring, Vander Wal, Pagoto, \& Hedeker, 2005), and hierarchical linear modeling (Raudenbush \& Bryk, 2002). The analyses incorporated a random intercepts, linear, and quadratic trends model with autoregressive errors, implemented via SAS PROC MIXED. This variance-covariance structure was selected after comparison with several other potential structures, as recommended by Verbeke and Molenberghs (2000). The use of mixedeffects regression modeling has several advantages over more traditional analytic approaches (e.g., repeated-measures analysis of variance). For example, such models allow for the inclusion of categorical and continuous covariates, as well as time-varying predictors, covariates, and outcome variables, in a single model. The primary analysis in the current study included continuous time-invariant variables (impulsivity, nicotine dependence, years smoked, and age), categorical time-invariant variables (depression history and sex), continuous time-varying predictors (taste and harshness of experimental cigarettes, which was measured at each session), a categorical time-varying predictor (experimental condition), and a time-varying outcome (negative affect) in one model.

Finally, random-effects regression models make assumptions about correlation of measurements over time that may be more realistic than other methods. For example, repeated-measures analysis of variance models assume that repeated measurements over time are equally correlated, with constant variance. Random-effects regression models with autoregressive errors, on the other hand, assume that one measurement will be more strongly correlated with measures at points closer in time and less strongly correlated with measures that are temporally distant (Gibbons et al., 1993; Hedeker, Flay, \& Petraitis, 1996).

Taste and harshness of the experimental cigarettes (both timevarying variables) were included as covariates in all analyses, as were history of major depression, years smoked, age, sex, nicotine dependence, time, and time ${ }^{2}$ (i.e., the quadratic effect of time). We opted to use this approach rather than orthogonal polynomials because it allowed for more meaningful interpretation of the regression estimates. Additionally, we expected that the pattern of negative affect over time, across conditions, would be quadratic (increasing from baseline to immediately following the mood induction and returning toward baseline at the two subsequent measurement points). Consequently, we postulated that the bestfitting model would include time ${ }^{2}$. Specific tests were conducted to determine the effects of impulsivity, condition, and their interaction on premood-induction negative affect and on time-related changes in negative affect (Impulsivity $\times$ Time, Condition $\times$ Time, Impulsivity $\times$ Condition $\times$ Time, Impulsivity $\times$ Time $^{2}$, Condition $\times$ Time $^{2}$, and Impulsivity $\times$ Condition $\times$ Time $^{2}$ interactions). Nonsignificant interaction terms were removed from the model in a backward manner (i.e., nonsignificant interactions with time $^{2}$ were removed first, then nonsignificant interactions with time were removed). Support for the hypothesis that impulsivity would predict change in negative affect over time in the nicotinized but not the de-nicotinized condition would be provided by a significant Impulsivity $\times$ Condition $\times$ Time interaction.

\section{Results}

\section{Preliminary Analyses}

As shown in Table 1, we first assessed the various relationships among demographic and experimental variables. Impulsivity was not significantly associated with sex, history of depression, baseline negative affect, nicotine dependence, cigarette consumption, or years smoked ( $p s>.05$ ). To test the validity of the negative mood induction, we calculated difference scores between POMS negative affect at baseline and after the mood induction in both the nicotinized $(M=29.2, S D=23.4)$ and de-nicotinized $(M=26.0, S D=21.3)$ conditions. There was no significant difference in change in negative affect between conditions, $t(69)=1.33 p=.20$. Additionally, postinduction negativeaffect scores were significantly higher than baseline scores in both the nicotinized, $t(69)=10.45 p<.01$, and denicotinized, $t(69)=9.97 p<.01$, conditions. Postinduction

Table 1

Relationships Among Demographic Variables

\begin{tabular}{|c|c|c|c|c|c|c|c|}
\hline Variable & 1 & 2 & 3 & 4 & 5 & 6 & 7 \\
\hline 1. Impulsivity & $-{ }^{\mathrm{a}}$ & & & & & & \\
\hline 2. History of depression & $.10^{\mathrm{a}}$ & $\overline{10^{\mathrm{b}}}$ & & & & & \\
\hline 3. Gender & $.03^{\mathrm{a}}$ & $.10^{\circ}$ & - & & & & \\
\hline 4. FTND & $-.15^{\mathrm{c}}$ & $.10^{\mathrm{a}}$ & $-.10^{\mathrm{a}}$ & - & & & \\
\hline 5. Cigarettes per day & $.02^{\mathrm{c}}$ & $.08^{\mathrm{a}}$ & $-.10^{\mathrm{a}}$ & $.36 * * \mathrm{c}$ & - & & \\
\hline 6. Years smoked & $-.17^{\mathrm{c}}$ & $.11^{\mathrm{a}}$ & $-.03^{\mathrm{a}}$ & $.15^{\mathrm{c}}$ & $.37^{* * \mathrm{c}}$ & - & \\
\hline 7. Age & $-.16^{\mathrm{c}}$ & $.14^{\mathrm{a}}$ & $-.02^{\mathrm{a}}$ & $.06^{\mathrm{c}}$ & $.42^{* * \mathrm{c}}$ & $90^{* * c}$ & - \\
\hline
\end{tabular}

Note. $\quad$ FTND $=$ Fagerström Test for Nicotine Dependence.

a Spearman's rho. ${ }^{5}$ Phi coefficient. ' ${ }^{c}$ Pearson's $r$.

$* p<.05$. ** $p<.01$. 


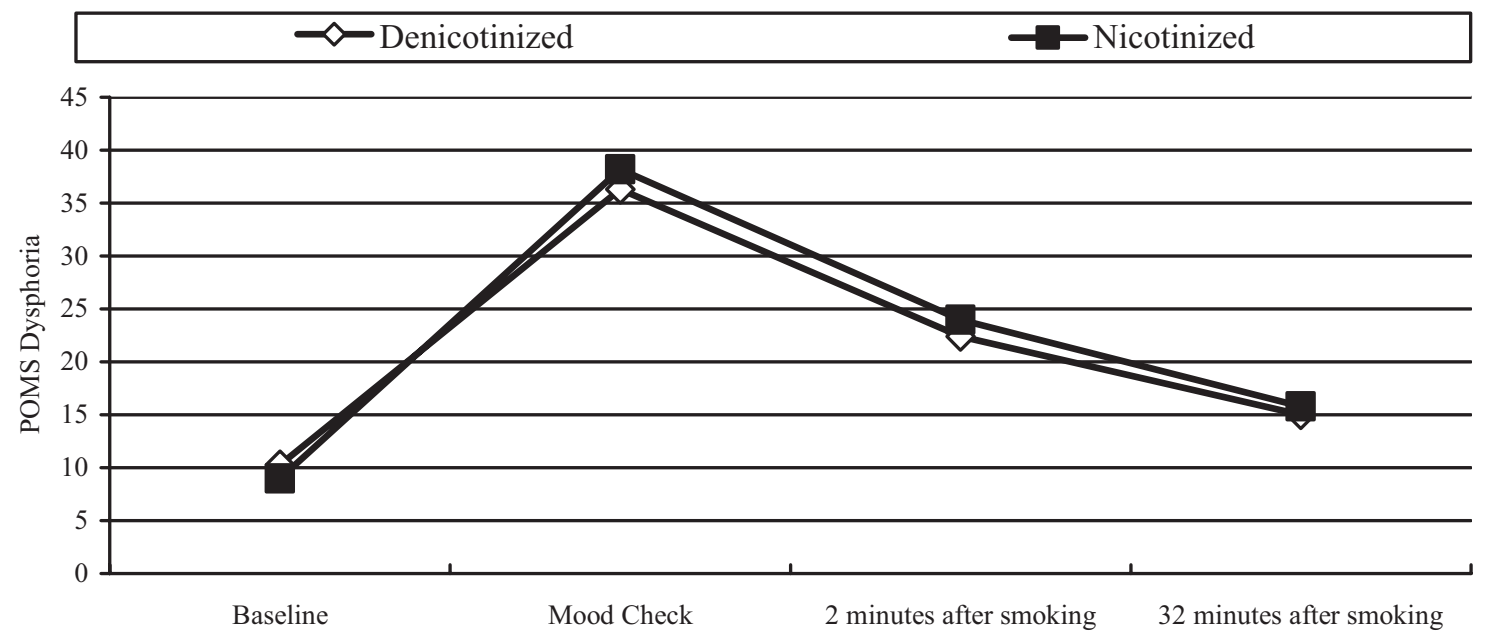

Figure 1. Mean negative affect over Time $\times$ Condition. POMS $=$ Profile of Mood States.

change in negative affect did not vary by condition order, $t(69)=1.20 p=.24$. Mean values for negative affect over time are shown in Figure 1.

\section{Primary Analyses}

The final mixed-effects regression model ${ }^{1}$ is shown in Table 2. Time, nicotine dependence, and years smoked were not significantly associated with negative affect. There was a significant quadratic time trend, indicating that negative affect rose following the mood induction but returned to-

Table 2

Mixed Effects Regression Model Predicting Negative Affect

\begin{tabular}{lrrc}
\hline \multicolumn{1}{c}{ Variable } & $\begin{array}{c}\text { Unstandardized } \\
\text { estimate }\end{array}$ & $S E$ & $t$ \\
\hline & Model $R^{2}=0.221$ & & \\
Covariates & -0.056 & 0.027 & $-2.07^{*}$ \\
Age & 0.071 & 0.684 & 0.10 \\
Nicotine & & & \\
Dependence & -4.170 & 2.054 & $-2.03^{*}$ \\
Gender & 0.804 & 0.369 & $2.18^{*}$ \\
Cigarette taste & 0.547 & 0.294 & 1.86 \\
Cigarette harshness & -0.163 & 0.236 & -0.69 \\
Years smoking & & & \\
History of major & 8.319 & 2.082 & $4.00^{* *}$ \\
$\quad$ depression & 0.410 & 0.387 & 1.06 \\
Effects of interest & -0.019 & 0.002 & $-8.11^{* *}$ \\
$\quad$ Time & 9.555 & 12.509 & 0.76 \\
Time & 16.438 & 10.285 & 1.60 \\
Condition & 0.464 & 0.169 & $2.75^{* *}$ \\
Condition $\times$ Time & -0.006 & 0.006 & -1.08 \\
Impulsivity & -0.630 & 0.183 & $-3.44^{* *}$ \\
Impulsivity $\times$ Time & & & \\
Impulsivity $\times$ Condition & & & \\
Impulsivity $\times$ Condition & 0.018 & 0.002 & $7.58^{* *}$ \\
$\quad \times$ Time &
\end{tabular}

Note. For the $t$ value associated with the variable time, $d f=67$. For all others $t$ values, $d f \mathrm{~s}=393$.

$* p<.05$. ** $p<.01$. ward baseline during the final two time points. Negative affect was related to age, such that younger smokers tended to experience higher levels of negative affect over time. The main effect of harshness of the experimental cigarettes was nonsignificant, $t(393)=1.86 p=.06$, but there was a trend toward those who rated experimental cigarettes as higher in harshness to report higher levels of negative affect over time. It is interesting to note that there was also a significant effect of taste, such that smokers who rated the experimental cigarettes as better tasting also tended to report higher levels of negative affect over time, $t(393)=2.18 p=.03$. The effect of sex on negative affect was also significant, $t(393)=-2.03 p=.04$, with female participants reporting more negative affect than men over time. Finally, history of major depression significantly predicted negative affect over time, $t(393)=4.00 p<.01$, such that those with a positive history reported more negative affect than their history-negative counterparts.

The mixed-effects regression model yielded a three-way Impulsivity $\times$ Condition $\times$ Time interaction, $t(393)=7.58$ $p<.01$. That is, impulsivity moderated the interaction between condition and time that predicted negative affect over time. To determine the direction of the interaction, we tested simple effects by using mixed-effects regression to test the Impulsivity $\times$ Time interaction within the nicotinized and de-nicotinized conditions separately.

We refit the primary model for each condition after removing the condition, Condition $\times$ Time, Condition $\times$ Impulsivity, and Condition $\times$ Impulsivity $\times$ Time terms.

\footnotetext{
${ }^{1}$ Model of negative affect over time is as follows: Negative affect $=\beta_{0}+\beta_{1}$ (age) $+\beta_{2}$ (nicotine dependence) $+\beta_{3}($ sex $)+$ $\beta_{4}$ (taste) $+\beta_{5}$ (harshness) $+\beta_{6}$ (years smoking) $+\beta_{7}$ (history of depression $)+\beta_{8}$ (time) $+\beta_{9}\left(\right.$ time $\left.^{2}\right)+\beta_{10}$ (condition) $+\beta_{11}$ (Time $\times$ Condition) $+\beta_{12}$ (impulsivity) $+\beta_{13}$ (Impulsivity $\times$ Time) $+\beta_{14}$ (Impulsivity $\times$ Condition) $+\beta_{15}$ (Impulsivity $\times$ Condition $\times$ Time). Negative affect, taste, harshness, time, time ${ }^{2}$, and condition were time-varying variables.
} 
Within the de-nicotinized condition, the Impulsivity $\times$ Time term was nonsignificant, $t(132)=0.47 p=.64$. However, within the nicotinized condition, there was a significant Impulsivity $\times$ Time interaction, $t(132)=2.98$ $p=.01$. In other words, impulsivity predicted postinduction change in negative affect after smoking a nicotinized cigarette but not after smoking a de-nicotinized cigarette.

To depict this relationship graphically, we again stratified the data by condition and calculated Pearson $r$ correlation coefficients between impulsivity and negative affect at each measurement point (baseline, mood check, 2 min after smoking, and 32 min after smoking). As Figure 2 indicates, in the de-nicotinized condition, impulsivity was significantly correlated with each negative affect measurement $(r s=.27-.39, p s<.05)$. In the nicotinized condition, impulsivity was significantly associated with negative affect at baseline $(r=.25, p=.04)$ and at mood check $(r=.40$, $p=.01)$ but not at $2 \min (r=.15, p=.22)$ or $32 \min (r=$ $.14, p=.23$ ) after smoking. In other words, heightened impulsivity was associated with higher levels of negative affect both before and after smoking in the de-nicotinized condition. In the nicotinized condition, higher impulsivity predicted elevated negative affect prior to smoking, but the relationship was nonsignificant at both postsmoking measurements. In sum, more impulsive smokers' tendency to report heightened negative affect was reduced after smoking a nicotinized cigarette but not after smoking a de-nicotinized cigarette.

\section{Discussion}

To our knowledge, the current study was the first to test the effect of nicotine on negative affect among impulsive smokers. We found that elevated impulsivity predicted heightened negative-affect relief after smoking a nicotinized but not a de-nicotinized cigarette following a negative mood induction. That is, for more impulsive smokers, nicotine appears to be a more powerful negative reinforcer than for their less impulsive counterparts. Additionally, because denicotinized cigarettes were used in the control condition, these data indicate that the finding can be attributed to nicotine, rather than to the sensory aspects of smoking.

These data are particularly interesting in light of the traditional view of the influence of impulsivity on substance abuse and other immediately reinforcing behaviors. Impulsive people have generally been thought to engage in such behaviors out of preference for small but immediately available reinforcers (e.g., drugs) over larger, delayed reinforcers (e.g., better health; Bickel \& Marsch, 2001; Bickel, Odum, \& Madden, 1999; Rachlin, 1995) as well as lack of consideration for the delayed, deleterious consequences (e.g., Dickman, 1990; Patton et al., 1995). The present study suggests a plausible reason for this preference: The immediately reinforcing effects of drugs could be more powerful for more impulsive users than for others. Here, nicotine was more negatively reinforcing for more impulsive smokers. Some extant research is consistent with the hypothesis that the positive- and negative-reinforcement properties of drugs may be disproportionately strong for those with heightened impulsivity. For example, Cascella, Nagoshi, Muntaner, and Walter (1994) reported that increased impulsivity predicted significantly stronger feelings of euphoria after intravenous cocaine use as compared with placebo. Additional indirect evidence is provided by findings noted earlier that indicated that more impulsive individuals may expect substances to alleviate negative affect to a greater extent than others do (e.g., Cooper et al., 2000; Hussong \& Chassin, 1994; Mann et al., 1987). To the extent that drugs are more reinforcing for more impulsive individuals, those individuals should have heightened expectations regarding the reinforcing effects of drugs. Additionally, contrary to previous sugges-

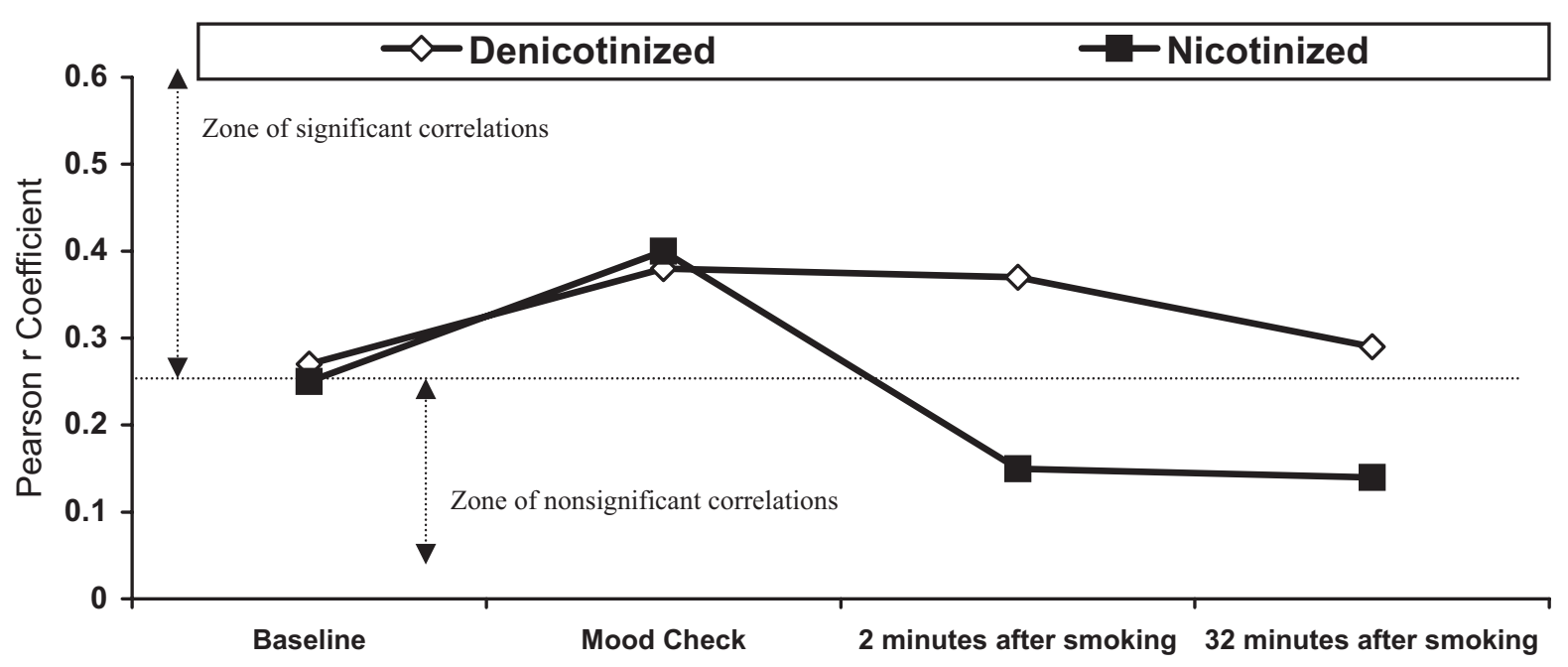

Figure 2. Pearson correlation coefficients depicting the association between impulsivity and negative affect over Time $\times$ Condition. All correlations above the horizontal line are significant $(p<.05)$, and all correlations below the line are nonsignificant $(p>.05)$. 
tions, more impulsive individuals may be just as likely as others to consider the potential negative consequences of drug use. Instead, if impulsive individuals derive greater reinforcement from drugs, they may be particularly susceptible to substance abuse despite equivalent knowledge of the potential consequences. Indeed, in the current study, we found that impulsivity was not associated $(r=-.04, p=$ .85) with scores on the Negative Consequences subscale of the Smoking Consequences Questionnaire (Copeland, Brandon, \& Quinn, 1995), indicating that more impulsive smokers were as aware of the harmful effects of smoking as their less impulsive counterparts. Alternatively, it is plausible that in the moment that they are deciding whether to smoke, impulsive smokers act without forethought, despite the fact that they are knowledgeable about the negative consequences at other times. In other words, smoking cues may elicit disproportionately strong urges to smoke among impulsive smokers, overwhelming their knowledge about future consequences.

Certain characteristics of the present study may limit its generalizability. First, the nature of the link between impulsivity and smoking has not been fully defined, and previous research suggests that impulsivity may be a consequence of substance use (Moeller \& Dougherty, 2002), which would cast doubt on the causal nature of the results in the present study. However, research also has indicated that heightened impulsivity is a prospective predictor of future substance abuse, including smoking (Baker et al., 2004). A second limitation of the present study is that smoking topography, which may vary significantly among smokers (Ahijevych, Gillespie, Demirci, \& Jagadeesh, 1996; Perkins et al., 2001), was not assessed. Previous research has indicated that de-nicotinized cigarettes can produce subjective reinforcing effects that resemble the subjective effects due to nicotinized cigarettes (Shahan, Bickel, Madden, \& Badger, 1999; Westman, Behm, \& Rose, 1996). Because participants were allowed to smoke ad libitum, we were unable to differentiate the possible effect of differences in smoking topography from the effect of nicotine.

In summary, the present findings suggest that nicotine may be disproportionately negatively reinforcing for more impulsive individuals in terms of alleviating negative affect. This result may explain previous findings that indicated that impulsivity is associated with heightened expectations regarding the negatively reinforcing properties of drugs and with increased drug use during bouts of negative affect. To the extent that nicotine reduces negative affect particularly effectively for them, more impulsive smokers would likely be disproportionately prone to smoking in the presence of negative affect. Because negative affect is a common consequent of nicotine withdrawal, it is not surprising that recent work has suggested more impulsive smokers may have greater difficulty quitting (Doran et al., 2004). Consequently, more impulsive smokers may derive particular benefit from cessation programs that focus on negative affect. Serotonergic antidepressant agents may also be effective cessation aids for impulsive smokers, given that they may reduce impulsivity (Johnson, Malow, Corrigan, \& West, 1993) as well as negative affect.

\section{References}

Ahijevych, K., Gillespie, J., Demirci, M., \& Jagadeesh, J. (1996). Menthol and nonmenthol cigarettes and smoke exposure in black and white women. Pharmacology Biochemistry and Behavior, 53, 355-360.

Arnett, P. A., \& Newman, J. P. (2000). Gray's three-arousal model: An empirical investigation. Personality and Individual Differences, 28, 1171-1189.

Baker, T. B., Brandon, T. H., \& Chassin, L. (2004). Motivational influences on cigarette smoking. Annual Review of Psychology, 55, 463-491.

Bickel, W. K., \& Marsch, L. A. (2001). Toward a behavioral economic understanding of drug dependence: Delay discounting processes. Addiction, 96, 73-86.

Bickel, W. K., Odum, A. L., \& Madden, G. J. (1999). Impulsivity and cigarette smoking: Delay discounting in current, never, and ex-smokers. Psychopharmacology, 146, 447-454.

Cascella, N. G., Nagoshi, C. T., Muntaner, C., \& Walter, D. (1994). Impulsiveness and subjective effects of intravenous cocaine administration in the laboratory. Journal of Substance Abuse, 6, 355-366.

Centers for Disease Control. (2002). Cigarette smoking among adults-United States 2000. Morbidity \& Mortality Weekly, 51, 642-645.

Clark, D. M., \& Teasdale, J. D. (1985). Constraints of the effects of mood on memory. Journal of Personality and Social Psychology, 48, 1595-1608.

Coccaro, E. F., Kavoussi, R. J., Sheline, Y. I., Berman, M. E., \& Csernansky, J. G. (1997). Impulsive aggression in personality disorder correlates with platelet $5-\mathrm{HT}_{2 \mathrm{~A}}$ receptor binding. $\mathrm{Neu}$ ropsychopharmacology, 16, 211-216.

Coccaro, E. F., Siever, L. J., Klar, H. M., Maurer, G., Cochrane, I. K., Cooper, T. B., et al. (1989). Serotonergic studies in patients with affective and personality disorders: Correlates with suicidal and impulsive aggressive behavior. Archives of General Psychiatry, 46, 587-599.

Cooper, M. L., Agocha, V. B., \& Sheldon, M. S. (2000). A motivational perspective on risky behaviors: The role of personality and affect regulatory processes. Journal of Personality, 68, 1059-1088.

Copeland, A. L., Brandon, T. H., \& Quinn, E. P. (1995). The Smoking Consequences Questionnaire-Adult: Measurement of smoking outcome expectancies of experienced smokers. Psychological Assessment, 7, 484-494.

Costa, P. T., \& McCrae, R. R. (1992). Revised NEO Personality Inventory (NEO-PI-R) and NEO Five-Factor Inventory (NEOFFI): Professional manual. Odessa, FL: Psychological Assessment Resources.

Dickman, S. J. (1990). Functional and dysfunctional impulsivity: Personality and cognitive correlates. Journal of Personality and Social Psychology, 58, 95-102.

Doran, N., Spring, B., McChargue, D., Pergadia, M., \& Richmond, M. (2004). Impulsivity and smoking relapse. Nicotine \& Tobacco Research, 6, 641-647.

Emmons, R. A., \& Diener, E. (1986). Influence of impulsivity and sociability on subjective well being. Journal of Personality and Social Psychology, 50, 1211-1215.

Evans, J., Platts, H., Lightman, S., \& Nutt, D. (2000). Impulsiveness and the prolactin response to $d$-fenfluramine. Psychopharmacology, 149, 147-152.

Gerrards-Hesse, A., Spies, K., \& Hesse, F. W. (1994). Experimental inductions of emotional states and their effectiveness: A review. British Journal of Psychology, 85, 55-78. 
Gibbons, R. D., Hedeker, D., Elkin, I., Waternaux, C., Kraemer, H. C., Greenhouse, J. B., et al. (1993). Some conceptual and statistical issues in analysis of longitudinal psychiatric data: Application to the NIMH Treatment of Depression Collaborative Research Program dataset. Archives of General Psychiatry, 50, 739-750.

Goldstein, H. (1995). Multilevel statistical models (2nd ed.). New York: Halsted Press.

Gray, J. A. (1970). The psychophysiological basis of introversionextraversion. Behaviour Research \& Therapy, 8, 249-266.

Gray, J. A. (1987). The neuropsychology of emotion and personality. In S. M. Stahl \& S. D. Iversen (Eds.), Cognitive neurochemistry (pp. 171-190). London: Oxford University Press.

Hall, S. M., Munoz, R. F., \& Reus, V. I. (1994). Cognitive behavioral intervention increases abstinence rates for depressive-history smokers. Journal of Consulting and Clinical Psychology, 62, 141-146.

Hall, S. M., Reus, V. I., Munoz, R. F., Sees, K. L., Hunfleet, G., Hartz, D. T., et al. (1998). Nortriptyline and cognitive-behavioral therapy in the treatment of cigarette smoking. Archives of General Psychiatry, 55, 683-690.

Heatherton, T. F., Kozlowski, L. T., Frecker, R. C., \& Fagerström, K. O. (1991). The Fagerström Test for Nicotine Dependence: A revision of the Fagerström Tolerance Questionnaire. British Journal of Addiction, 86, 1119-1127.

Hedeker, D., Flay, B. R., \& Petraitis, J. (1996). Estimating individual influences of behavioral intentions: An application of random-effects modeling to the theory of reasoned action. Journal of Consulting and Clinical Psychology, 64, 109-120.

Hitsman, B., Borrelli, B., McChargue, D. E., Spring, B., \& Niaura, R. (2003). History of depression and smoking cessation outcome: A meta-analysis. Journal of Consulting and Clinical Psychology, 71, 657-663.

Hughes, J. R., Higgins, S. T., \& Hatsukami, D. (1990). Effects of abstinence from tobacco: A critical review. In L. T. Kozlowski \& H. M. Annis (Eds.), Recent advances in alcohol and drug problems (Vol. 10, pp. 317-398). New York: Plenum Press.

Hussong, A. M., \& Chassin, L. (1994). The stress-negative affect model of adolescent alcohol use: Disaggregating negative affect. Journal of Studies on Alcohol, 55, 707-718.

Jeffery, R. W., Hennrikus, D. J., Lando, H. A., Murray, D. M., \& Liu, J. W. (2000). Reconciling conflicting findings regarding postcessation weight concerns and success in smoking cessation. Health Psychology, 19, 242-246.

Johnson, W. L., Malow, R. M., Corrigan, S. A., \& West, J. A. (1993). Impulsive behavior and substance abuse. In W. McCown, M. Shure, \& J. Johnson (Eds.), The impulsive client: Theory, research, and treatment (pp. 225-246). Washington, DC: American Psychological Association.

Kassel, J. D., Shiffman, S., Gnys, M., Paty, J., \& Zettler-Segal, M. (1994). Psychosocial and personality differences in chippers and regular smokers. Addictive Behaviors, 19, 565-575.

Kenford, S. L., Smith, S. S., Wetter, D. W., Jorenby, D. E., Fiore, M. C., \& Baker, T. B. (2002). Predicting relapse back to smoking: Contrasting affective and physical models of dependence. Journal of Consulting and Clinical Psychology, 70, 216227.

Khine, K., Luff, J. A., Rubinow, D. R., \& Schmidt, P. J. (2003). The perimenopause and mood disorders. Primary Psychiatry, 10, 44-47.

LeMarquand, D. G., Pihl, R. O., Young, S. N., Tremblay, R. E., Seguin, J. R., Palmour, R. M., \& Benkelfat, C. (1998). Trypto- phan depletion, executive functions, and disinhibition in aggressive, adolescent males. Neuropsychopharmacology, 19, 333341.

Mann, L. M., Chassin, L., \& Sher, K. J. (1987). Alcohol expectancies and the risk for alcoholism. Journal of Consulting and Clinical Psychology, 55, 411-417.

Manuck, S. B., Flory, J. D., McCaffery, J. M., Matthews, K. A., Mann, J. J., \& Muldoon, M. F. (1998). Aggression, impulsivity, and central nervous system serotonergic responsivity in a nonpatient sample. Neuropsychopharmacology, 19, 287-299.

Martin, L. E., \& Potts, G. F. (2004). Reward sensitivity in impulsivity. NeuroReport, 15, 1519-1522.

Martin, M. (1990). On the induction of mood. Clinical Psychology Review, 10, 669-697.

McNair, D. M., Lorr, M., \& Droppleman, L. F. (1971). Profile of Mood States manual. San Diego, CA: EdITS.

Meyers, A. W., Klesges, R. C., Winders, S. E., Ward, K. D., Peterson, B. A., \& Eck, L. H. (1997). Are weight concerns predictive of smoking cessation? A prospective analysis. Journal of Consulting and Clinical Psychology, 65, 448-452.

Mitchell, S. H. (1999). Measures of impulsivity in cigarette smokers and non-smokers. Psychopharmacology, 146, 455-464.

Moeller, F. G., \& Dougherty, D. M. (2002). Impulsivity and substance abuse: What is the connection? Addictive Disorders \& Their Treatment, 1, 3-10.

Moeller, F. G., Dougherty, D. M., Steinberg, J. L., Swann, A. C., Silverman, P. B., Ruiz, P., \& Barratt, E. S. (2002). Heavy "ecstasy" use is associated with increased impulsivity. Addictive Disorders \& Their Treatment, 1, 47-52.

Mulder, R. T., \& Joyce, P. T. (2002). Relationship of temperament and behaviour measures to the prolactin response to fenfluramine in depressed men. Psychiatry Research, 109, 221-228.

Parrott, A. C. (1994). Individual differences in stress and arousal during cigarette smoking. Psychopharmacology, 116, 389-396.

Parrott, A. C. (1999). Does cigarette smoking cause stress? American Psychologist, 54, 817-820.

Parrott, A. C., Garnham, N. J., Wesnes, K., \& Pincock, C. (1996). Cigarette smoking and abstinence: Comparative effects upon cognitive task performance and mood state over 24 hours. Human Psychopharmacology, 11, 391-400.

Patton, J. H., Stanford, M. S., \& Barratt, E. S. (1995). Factor structure of the Barratt Impulsiveness Scale. Journal of Clinical Psychology, 51, 768-774.

Perkins, K. A., Gerlach, D., Vender, J., Grobe, J., Meeker, J., \& Hutchison, S. (2001). Sex differences in the subjective and reinforcing effects of visual and olfactory cigarette smoke stimuli. Nicotine \& Tobacco Research, 3, 141-150.

Persky, I., Spring, B., Vander Wal, J. S., Pagoto, S., \& Hedeker, D. (2005). Adherence across behavioral domains in treatment promoting smoking cessation plus weight control. Health Psychology, 24, 153-160.

Piasecki, T. M., Kenford, S. L., Smith, S. S., Fiore, M. C., \& Baker, T. B. (1997). Listening to nicotine: Negative affect and the smoking withdrawal conundrum. Psychological Science, 8, 184-189.

Pickworth, W. B., Fant, R. V., Nelson, R. A., Rohrer, M. S., \& Henningfield, J. E. (1999). Pharmacodynamic effects of new de-nicotinized cigarettes. Nicotine \& Tobacco Research, 14, 357-364.

Pomerleau, C. S., Carton, S. M., Lutzke, M. L., \& Flessland, K. A. (1994). Reliability of the Fagerström Tolerance Questionnaire and the Fagerstrom Test for Nicotine Dependence. Addictive Behaviors, 19, 33-39.

Rachlin, H. (1995). The value of temporal patterns in behavior. Current Directions in Psychological Science, 4, 188-192. 
Raudenbush, S. W., \& Bryk, A. S. (2002). Hierarchical linear models (2nd ed.). Thousand Oaks, CA: Sage.

Reist, C., Helmeste, D., Albers, L., Chhay, H., \& Tang, S. (1996). Serotonin indices and impulsivity in normal volunteers. Psychiatry Research, 60, 177-184.

Salin-Pascual, R. J. (2002a). Nicotine antidepressant effects as a predictor of response to desimipramine or fluoxetine in nonsmoking major depressed patients. Salud Mental, 25, 16-20.

Salin-Pascual, R. J. (2002b). Relationship between mood improvement and sleep changes with acute nicotine administration in non-smoking major depressed patients. Revista de Investigación Clínica, 54, 36-40.

Salin-Pascual, R. J., \& Drucker-Colin, R. (1998). A novel effect of nicotine on mood and sleep in major depression. NeuroReport, 9, 57-60.

Salin-Pascual, R. J., Rosas, M., Jimenez-Genchi, A., Rivera-Meza, B. L., \& Delgado-Parra, V. (1996). Antidepressant effect of transdermal nicotine patches in nonsmoking patients with major depression. Journal of Clinical Psychiatry, 57, 387-389.

Shahan, T. A., Bickel, W. K., Madden, G. J., \& Badger, G. J. (1999). Comparing the reinforcing efficacy of nicotine containing and de-nicotinized cigarettes: A behavioral economic analysis. Psychopharmacology, 147, 210-216.

Sher, K. J. (1987). Stress response dampening. In H. T. Blane \& K. E. Leonard (Eds.), Psychological theories of drinking and alcoholism (pp. 227-271). New York: Guilford Press.

Shiffman, S., Paty, J. A., Gnys, M., Kassel, J. A., \& Hickox, M. (1996). First lapses to smoking: Within-subjects analysis of real-time reports. Journal of Consulting and Clinical Psychology, 64, 366-379.

Soares, C. N., \& Almeida, O. P. (2001). Depression during the perimenopause. Archives of General Psychiatry, 58, 306.

Spitzer, R. L., Williams, J. B., Gibbon, M., \& First, M. B. (1992). The Structured Clinical Interview for DSM-III-R (SCID): I. History, rationale, and description. Archives of General Psychiatry, 49, 624-629.
Stanford, M. S., Greve, K. W., Boudreaux, J. K., Mathias, C. W., \& Brumbelow, J. L. (1996). Impulsiveness and risk-taking behavior: Comparison of high school and college students using the Barratt Impulsiveness Scale. Personality \& Individual Differences, 21, 1073-1075.

U.S. Department of Health and Human Services. (2000). The health benefits of smoking cessation: A report of the Surgeon General (DHHS Publication No. CDC 90-8416). Rockville, MD: U.S. Department of Health and Human Services, Public Health Service, Centers for Disease Control, Center for Health Promotion and Education, Office On Smoking and Health.

Verbeke, G., \& Molenberghs, G. (2000). Linear mixed models for longitudinal data. New York: Springer.

Walderhaug, E., Lunde, H., Nordvic, J. E., Landro, N. I., Refsum, H., \& Magnusson, A. (2002). Lowering of serotonin by rapid tryptophan depletion increases impulsiveness in normal individuals. Psychopharmacology, 164, 385-391.

Westman, E. C., Behm, F. M., \& Rose, J. E. (1996). Dissociating the nicotine and airway sensory effects of smoking. Pharmacology Biochemistry and Behavior, 53, 309-315.

Wetter, D. W., Carmack, C. L., Anderson, C. B., Moore, C. A., DeMoor, C. A., Cinciripini, P. M., \& Hirshkowitz, M. (2000). Tobacco withdrawal signs and symptoms among women with and without a history of depression. Experimental and Clinical Psychopharmacology, 8, 88-96.

Williams, J. B. W., Gibbon, M., First, M. B., Spitzer, R. L., Davies, R. M., Borus, J., et al. (1992). The Structured Clinical Interview for $D S M-I I I-R$ (SCID). Multisite test-retest reliability. Archives of General Psychiatry, 49, 630-636.

Received September 17, 2004

Revision received August 11, 2005

Accepted August 23, 2005 